\title{
A violência na es cola: conflitualidade social e ações civilizatórias
}

J osé Vicente Tavares dos Santos

Universida de Fe de ral do Rio Gran de do Sul

Resumo

O reconhecimento da violência no espaço escolar como um en clausuramento do gesto e da palavra, uma das novas questões sociais globais, parece ser um caminho interpretativo fecundo. O que está em risco é a função da escola de socialização das no vas gerações, pois a instituição escolar aparece enquanto locus de explosão de conflitos sociais em, pelo menos, 23 países nos quaisavi o lên cianaescolafoicon si deradaumfenô meno desociedade.

A compreensão das relações entre a escola e as práticas da violência passam pela reconstrução da complexidade das relações so ci a isna esco la. No caso em estu do - a vi o lên cia no espaço escolar, na cidade de Porto Alegre, entre 1996 e 2000 - são as combinações entre as relações de classe e as relações en tregrupos culturais que permitem uma explicação: espaço social marcado por um desencontro entre a instituição escolar e as particularidades culturais das populações pobres das grandes cidades.

Os programas contra a violência que existem nos principais países, inclusive em algumas escolas municipais de Porto Alegre, desenvolvem a metodologia de mediação de conflitos como uma das propostas de pacificação do espaço escolar: uma prática de negociação instaurada no interior da escola, em especial nos próprios grupos de alunos, atra vés, por exem plo, da idéia demediação pelos pares, de forma a criar responsabilidades e tentar satisfazer as necessidades dos jovens, mediante o desenvolvimento de um ambiente solidário, humanista e cooperativo.

Palavras-chave

Escola - Violência - Ação Social - Conflitualidade social.

Correspondência:

J osé Vi cen te T. dos San tos

Av. Lu cas de Oli vei ra, 909

ap. 702

90440-011 - Por to Ale gre - RS

e-mail:

jvicente@portoweb.com.br 


\section{Viole nce at school: social conflictuality and civilizatory actions}

J osé Vicente Tavares dos Santos

Universidade Federal do Rio Gran dedo Sul

\section{Abstract}

Recognizing violence within the school as an imprisonment of gesture and word - one of the new global social issues - seems a fruitful interpretative path. What is at risk is the school function of socializing the new generations, because the school body appears as a locus of explosion of social conflicts in at least twenty-three countries where violence at school was regarded as a social phenomenon.

The understanding of the relationships between the school and violent practices depends on the reconstruction of the complexity of social relations at school. In the case under study - the violence within the schools in the Brazilian city of Porto A legre between 1996 and 2000 - the combination of class relationships and group relationships will afford an explanation: a social space characterized by a mismatch between the school and the cultural features of the poor people of big cities.

The programs against violence implemented in some schools of Porto A legre have carried out the methodology of conflict mediation as one of the proposals to pacify the school space. This is a practice of negotiation established within the school, especially within the groups of pupils - through, for instance, the idea of peer mediation - as a way of creating responsibilities and to meet the needs of youngsters via the establishment of a solidary, humanist and cooperative environment.

Keywords

School - Violence - Social action - Social conflictuality.

\section{Correspondence:}

J osé Vicen te T. dos San tos

Av. Lucas de Oliveira, 909

ap. 702

90440-011 - Por to Ale gre - RS

e-mail:

jvicente@portoweb.com.br 
Partimos do reconhecimento de que hou ve uma profunda mutação na sociedade contemporânea, nos últimos vinte anos, o que pode ser definido como realização de um capitalismo tardio ou de processo de formação da sociedade global, a qual aponta para a era do globalismo (Ian ni, 1996, 1992; Har vey, 1993).

As relações de sociabilidade passam por uma nova mutação, mediante processos simultâneos de integração comunitária e de fragmentação social, de massificação e de individualização, de seleção e de exclusão social. Nesse passo, novos dilemas e problemas sociais emergem no horizonte planetário, configurando novas questões sociais globais. (Cf. Castel, 1998; Giddens, 1966; Jameson, 1996; Sousa Santos, 1994).

Como efeito dosprocessosdefrag men tação social e de exclusão econômica e social, emergem as práticas de violência como norma social particular de amplos grupos da sociedade, presentes em múltiplas dimensões da violência social e política contemporânea. A interação social passa a ser marcada por estilos violentos de sociabilidade, invertendo as expectativas do processo civilizatório (Elias, 1990, 1993).

O reconhecimentodaviolên cia no espaço escolar como uma das novas questões sociais globais parece ser um caminho interpretativo fecundo desse fenômeno social caracterizado como um enclausuramento do gesto e da palavra.

Essa nova questão so cial glo bal, con figurada por manifestações de violência contra a pessoa, por roubos, furtos e depredações, até mesmo por assassinatos, que se repetem em um conjunto expressivo de sociedades nos últimos dez anos, vem evidenciando que estamos em face de uma conflitualidade que coloca em risco a fun ção so cial da esco la deso ci alização das no vasgerações: o quesepercebeéa insti tu ição escolar enquanto um locus de ex plo são de conflitos sociais em pelo menos 23 países, nos quais a questão da violência no espaço escolar foi considerada um fenômeno de sociedade (Ohsako, 1997; Charlot, 1997).

Devemos sempre estar conscientes, ao analisar o fenômeno da violência na escola, de que estamos em face de uma relação professor/aluno, na qual este está desfavorecido em uma relação de poder, pois a violência, ao contrário do senso comum que criminaliza o infante, produz vítimas justamente entre as crianças e os adolescentes.

A compreensão das relações entre a escola e as práticas da violência passa pela reconstrução da complexidade das relações sociais que estão presentes no espaço social da escola. No caso em estudo - a violência no espaço escolar, na cidade de Porto Alegre, en tre 1996 e 2000 - , serão exatamente as combinações entre as relações de classe e as relaçõesen tregru poscul tu raisquepermi tirão uma abordagem explicativa da presença, na instituição escolar, de práticas de violência. ${ }^{1}$

Deparamo-nos com uma forma de sociabilidade, a violência, na qual se dá a afirmação de poderes legitimados por uma determina danorma so cial, o quelhecon ferea forma de controle social: a violência configura-se como um dispositivo de controle, aberto e contínuo. Força, coerção e dano em relação ao ou tro, en quan to atosdeexcesso, presen tes nas relações de poder - seja no nível macro, do Estado, seja no nível micro, entre os grupos sociais - , vêm a configurar a violência so cial contemporânea. A violência seria a relaçãosocial de excesso de poderqueimpede

1. A exposição completa dos resultados desta pesquisa-ação, bem com uma série de textos complementares, estão em Tavares dos Santos (1999). Neste texto foram ampliadas nossas análises anteriores, publicadas em: Tavares dos Santos, J.V. - 0 muro da escola e as práticas de violência. In: Heron da Silva, I. \& Azevedo, J.C. Reestruturação curricular: teoria e prática no cotidiano da escola. Petrópolis: Vozes, 1995. p. 228-234; Tavares dos Santos (1999); Tavares dos Santos, J.V. Os limites da cidadania no espaço escolar, em tempo de globalização (por uma explicação sociológica da violência na escola). In: Azevedo, J osé Clóvis etal. (orgs.). Utopia e democracia na educação cidadã. Porto Alegre: Ed. da UFRGS/SMED - PMPA, 2000. p. 127-140. 
o reconhecimento do outro - pessoa, classe, gênero ou raça - mediante o uso da força ou da coerção, provocando algum tipo de dano, configurando o oposto daspossibilidadesdaso ciedade democrática contemporânea (Tavares dos Santos,1999).

Nesse diagrama, há um espaço social marcado por um desencontro entre a instituição escolar e as particularidades culturais das populações pobres das grandes cidades(Zaluar, 1992, p. 37-54). Saliente-se, ainda, que a relação da escola com as particularidades culturais dos grupos que compõem o espaço social local em que ela se localiza é marcada por uma violência simbólica do saber escolar, exercida, muitas vezes, por hábitos sociais, pelos professores efun cionários da instituição: uma relação de poder que impõe um conjunto de valores ao conjunto da população envolvida. Por outra parte, há uma complexidade de tempos sociais na relação entre a esco laeo meio so cial: asin con gruên ci as do tempo social no qual a escola se insere, marcado por uma disparidade entre as expectativas diferenciadas do papel da educação escolar como meio de socialização. ${ }^{2}$

A metodologia da investigação consistiu na pesquisa-ação, aliada a uma série de outros procedimentos. Constituímos uma base de dados sobre a violência na escola, na qual há registros sobre atos de violência contra 0 patrimônio, contra a pessoa e atos de ações co letivas contra a violência no espaço escolar. Essa base cobre o período de 1990 a 2000, em bora a maioria dos registros seja dos anos de 1997 e 2000. As informações qualitativas recoIhidas na base de dados foram analisadas mediante 0 uso do programa de indexação automática e de inferência interpretativa, 0 NUD*IST.4. ${ }^{3}$

\section{A mundialização da violência no espaço escolar}

A violência não ocorre somente nos países periféricos, como se constata atravésdaim pren- sa internacional, que noticia freqüentemente esses fatos nos países centrais do sistema capitalista. ${ }^{4}$ Podemos vislumbrar, além de um crescente número de publicações, ciclos de debates sobre esse assunto. Algumas experiências internacionais podem nos dar lições acerca da violência na escola, assim como trazer sugestões a fim de visualizar iniciativas para reduzir tais fenômenos no espaço escolar.

$\mathrm{Na}$ França, o fenômeno da violência na escola é debatido, desde 1981, pelo menos, no âmbito da FEN - Federação da Educação Nacional, entidade que, mais recentemente, em 1994, organizou um colóquio sobre a "Violência e a missão Educativa". Nessa ocasião, Eric Debarbieux afirmava:

Nossa hipótese de base é que 0 crescimento atual do sentimento de insegurança no meio escolar está ligado a uma mutação global da relação com a cri an ça e os jo vens e a uma cri se do sen ti do do ofício do edu ca dor. (Eric, 1997)

Ele salientou ainda que "o prolongamento da adolescência, o medo do desemprego, os novos modelos familiares, geram uma crise de identidade entre os professores e os alunos que freqüentemente estão na base dos conflitos". Fazia, portanto, uma relação entre a exclusão e a violência, indicando que a inserção no bairro e os laços sociais são um ponto nodal, inclusive determinando uma lei de proximidade, pois são os alunos mais próximos a indivíduos violentos que sofrem mais violência.

2. Sposito, s.d., p. 161-178; Fukui, Lia. Segurança nas escolas. In: Zaluar, Alba (org.) Violência e educação. São Paulo: Cortez, 1992. p. 103-125.

3. @QSR NUD*ST.4; Tavares dos Santos, J.V. As possibilidades das Metodologias Informacionais nas práticas sociológicas: por um novo padrão de trabalho para os sociólogos do Século XXI. In: Revista sociologias. Porto Alegre. PPG - Sociologia do IFCH da UFRGS, ano 3, n. 5, p. 114-146, jan-jun de 2001.

4. Violences à l'école, violences de l'école. Dossiê do jornal Le Monde Diplomatique, Paris, ano 47, n. 559, p. 4-7, out/2000. 
Debarbieux, após dirigir uma grande pesquisa sobre a violência no meio escolar, identificou três tipos de violência na escola: a violência penal, dos crimes e delitos; as incivilidades, tendo assim denominado os conflitos de civilidades; e o sentimento de insegurança. Conclu iu pela correlação en treex clu são so ciale violência escolar, pois a violência é determinada socialmente, mas também percebeu um aumen to deatosviolen toscon tra ospro fesso rese de violências cometidas por grupos de alunos (Debarbieux, 1999).

A violência nasce de uma lógica da exclusão, pois con sisteem um discur so da recu sa: " $A$ violência nasce da palavra emparedada" (Colombier, 1989, p. 68). Por conseguinte, afirmam Colombier e outros autores da pedagogia institucional que é fundamental instaurar uma instituição escolar com regras, leis e esferas de poder: por exemplo, em cada Conselho de Classe, discute-se uma lei fundamental que fixa os limites nos quais vão se exercer os poderes de cada um: "A lei fundamental é colocada e imposta no princípio como limite do campo do possível" (idem, p. 101). Nessa proposta, o objetivo é fortalecer as instituições, criando regras livremente consentidas e levando em conta os conflitos de forma a organizar meios para sua resolução: contra a palavra emparedada, impõe-serestau raraau to ridadelegítimado professor e a mediação da linguagem mediante uma enunciação legítima, na qual se afirma a pedagogia do desejo e das forças da vida, percebendo-se a instituição escolar como uma rede de relações.

Se quisermos, entretanto, construir a cidadanianaescola, in sisteDefrance(1992), devemos também reconhecer, e superar, a violência institucional, que passa "por regulamentos, estruturas organizacionais, relações de poder institucionalizadas". Assinala, então, os fatores principais da violência: o tamanho dos estabelecimentos escolares e o corpo de professores e funcionários, a taxa de fracasso escolar, a qualidade da orientação aos alunos e a própria violência da instituição escolar repressiva, seletiva e competitiva. Seriam várias facetas de uma "violência simbólica", pela qual a autoridade do poder e do saber professoral seria imposta aos estudantes (Defrance, p. 45).

A violência na escola, na França, segundo Debarbieux, está ligada a uma sociologia da exclusão, caracterizando-se por três formas: delitos e vitimização, tais como extorsão, roubos, agressões, racismos e insultos; um clima no estabelecimento escolarmarcado por incivilidades; e por um sentimento de insegurança que reflete a percepção da violência. Existem, porém, segundo ele, duas mudanças recentes nesse quadro: aumento das violências contra o professor em sala de aula; violência praticada em atos grupais e mais duros (Debardieux, 1999).

Talvez fosse mais apropriado denominarmos tais incivilidades como um conflito de civilidades, pois entre professores e alunos há portadores de diferentes normas de conduta, o que se manifestaporformasmenores, moleculares e cotidianas de violência no espaço escolar, indicando a difícil questão da conivência entre grupos sociais que utilizam diversos códigos culturais nas relações de socialidade (Charlot \& Emin, 1997).

Estamos, em grande medida, em facede um conflito de códigos de con du ta, ou conflito de civilidades, como tem sido apontado nos estudos sobre o tema na França e, mais recentemente, em criterioso estudo de caso realizado em liceus de Montevidéu, Uruguai. Sobre esses, Nilia Viscardi (1999) concluiu:

Quanto às característicasqueassu me a violência no espaço escolar, tanto em espaçosabertos quanto em situações de classe, pode observar-se que a maioria dessas violências constituem incivilidades. (...) uma crise de convivência, uma dificuldade para socializar os jovens no marco dos valores que a escola tem por objetivo incutir (...). 
Algumas constatações podem resumir a situação francesa da violência no espaço escolar, segundo Peralva (1997):

A primeira é de que a violência deriva em parte da incapacidade atual da escola em fundar um modelo de ordem (...). A segunda constatação é de que a violência, pelo menos em parte, origina-se da configuração (...) de um conflito, cujo cen tro éojul gamen to esco lar. A tercei raconstatação (...) [0] desenvolvimento de uma cultura da violência encravada no universo juvenil.

Da experiência francesa, podemos extrair condições e procedimentos para superar a violência: desenvolver a possibilidade de falarmediante a instauração de lugares para as palavras, resgatando o sentido da linguagem, e a palavra tomando o lugar dos atos de violência. Para tanto, a escola precisaria expandir 0 saber escrever e dar condições para publicar, assegurando instrumentos que fazem da palavra e da escrita um poder. Ao mesmo tempo, esse diálogo, paciente, obstinado, pedagógico, instaura um respeito ao outro, com ações e sentimentos de reciprocidade que podem ajudar a eliminar a violência, construindo possibilidades do encontro. Esse aprendizado real da liberdade vivida no cotidiano, através de ações de ajuda mútua escolar, de relações com a vida asso ciati valo cal edereco nhecimen to do plu ralismo cultural, no espaço escolar, afirmam uma primeira lição nas ações contra a violência na escola.

No caso do Canadá, cujas grandes cidades são atualmente marcadas pela variedade étnica e cultural, reconhece- se uma determinação social da violência na escola, pois a violência entre os jovens é semelhante à que ocorre sob os modelos culturais que se encontram em seu meio social:

Querer compreender e agir sobre as agressões dos jo vensem meio es co lar exi ge le varem con ta os comportamentos dos diversos atores, as es- truturas organizacionais e os valores dominantes. Deve-se igualmente dar um lugar importante às relações sociais que são portadoras de desigualdadee de injustiça para muitos alunos. (Herbert, 1999, p. 27-28)

Alguns fatores são realçados por Herbert para explicar as manifestações de violência no meio escolar: fatores individuais (como aqueles que afetam a auto-estima dos jovens), fatores familiares e fatores da própria es co la, como o tipo de re gras do jogo que nela impera. Insiste, pois, sobre o próprio sistema de produção e os valores (1999, p. 37-38).

No que se refere aos programas de prevenção da violência, ele sugere um modelo eco ló gi co que visa "ana li sar eagir so bre osfa. tores socioambientais", de modo a "mobilizar as forças sociais" capazes de contribuir com a superação da violência na escola. Talvez seja essa a lição que a experiência canadense recente possa nos transmitir.

A violência na escola é objeto de debates nos Estados Unidos há três décadas: 0 Instituto Nacional de Educação afirmava, já em 1978, que a violência na escola era um problema nacional. Desde então, existe um vasto debate, entre educadores e sociólogos, sobre a identificação dos fatores que contribuiriam para a violência na escola: mudança de padrões da família e da vida comunitária; falta de espaços para tecer laços sociais; ausência de associações, configurando uma condição de multidão. ${ }^{5}$ Nos EUA, a sociedade redefiniu a violên ciacomo normal eaceitável, principalmente na mídia, o que é potencializado pelo fácil acesso a armas e a drogas. Compreende-se, então, afirmam vários autores, que as pessoas se sintam habilitadas para a violência e toleradas, o que se confirmaria pelo fato de a violên ciaserexerci daen trepessoas conhecidas na escola.

5. Cf. Hyman, (1997); J ohnson, (1995); Kreiner, (1966); Remboldt (1994). 
Os programas para prevenir a violência, por um lado, são caracterizados pelo aumento de medidas repressivas (detectores de metais, penalização dos jovens e adolescentes), principalmente nas grandes cidades (Lucas, 1997, p. 70-95); por outro lado, pautam-se pelo reconhecimento do conflito na escola como uma conflitualidade positiva, desenvolvendo práticas de negociação e de resolução de conflitos por meio, por exemplo, da mediação pelos pares. ${ }^{6}$ Reconhecer a conflitualidade e a agressividade, como elementos dinâmicos do espaço escolar, significa propor intervenções sobre os atos de violência, as quais podem se dar pela satisfação de necessidades das crianças e jovens, criando um ambiente cooperativo e humanista, induzindo relacionamentos positivos e duradouros. Nesse quadro, a utilização de um tempo não-escolar, para atividades de interação com a comunidade, e as práticas de mediação e de negociação de confli tosparecem seras estratégias privilegiadas pelos educadores humanistas norte- americanos.

As lições das experiências francesas, canadenses e norte-americanas indicam estratégias de reconhecimento da violência no espaço escolar como um fenômeno social, no qual a violência surge como a afirmação do silêncio e de um enclausuramento do gesto e da palavra. Para se poder afirmar o discurso do diálogo, impõe-se, portanto, não somente o fortalecimento das instituições escolares, como também a afirmação do espaço social multicultural como o reconhecimento do conflito como potencialmente criador de laços sociais. Dessa forma, é condição fundamental que se exerça a negociação enquanto estratégia de resolução de conflitos na instituição escolar.
A violência nas escolas municipais de Porto Alegre

A pesquisa realizada nas escolas municipais, diretamente por nós ou por intermédio de formulários enviados a elas, e outros levantamentos feitos pela Guarda Municipal de Porto Alegre possibilitam uma visão geral dos atos relacionados à violência.

Foram realizados do is levantamentos: 0 primeiro em 1998, abrangendo também uma memória de fatos ocorridos anteriormente, evocados desde o ano de 1990, embora a maior parte dos registros se referisse ao ano de 1997; o segundo foi realizado em 2000, após cin co anosdetraba lho nases co las, refletindo portanto uma melhor qualidade de informações, fruto da confiança construída entre a equipe de pesquisa e as direções das escolas municipais de Porto Alegre. A série temporal expressa as dificuldades em se obter tais tipos de informações, pois apenas nos anos em que houve maior presença dos pesquisadores solicitando informações - nos anos de 1996, 1997 e 2000 - é que foram meIhor identificadas as ações.

0 Quadro 1 indica que houve um sensível aumento dos acontecimentos relacionados à violência na escola, fruto da observação mais confiável. Os eventos relacionados ao

6. Cf. Hyman, (1997, p. 312-316); Kreiner, (1966, p. 41-55); Remboldt, (1994, p. 29-33).

QUADRO 1. A violência na escola - Porto Alegre

Escolas Municipais - 1998-2000

\begin{tabular}{|l|c|c|c|c|c|}
\hline & Patrimônio & Pessoa & Incivilidade & ACVE & Total por Escola \\
\hline $1990-1998$ & 74 & 120 & 0 & 10 & 204 \\
\hline 2000 & 108 & 102 & 110 & 86 & 406 \\
\hline TOTAL & 182 & 222 & 110 & 96 & 610 \\
\hline
\end{tabular}


patrimônio passaram de 74 a 108, chegando a 182 casos; aqueles que dizem respeito a atos contra as pessoas diminuíram de 120 a 102 registros, totalizando 222. Provavelmente essa aparente diminuição deva-se ao fato de que no levantamento de 2000 introduzimos a categoriade incivilidade, a qual in di cou 110 casos: se agregarmos as duas categorias, atos contra a pessoa e incivilidade, atin gi ría mos332 casosde violência, física ou simbólica, con traaspesso as nos últimos anos.

A novidade maior do segundo levantamento foi a realização de atos contra a violência na escola: passaram de 10 a 86, totalizando 96 no período. Isso revela que a coletividade escolar está reagindo mediante uma série de ações coletivas contra a violência na escola.

A cartografia desses atos de violência revela que há uma distribuição espacial relativamente homóloga: os atos de violência localizam-se nas regiões periféricas da cidade, mas também são nelas que podemos identificar as mobilizações contra a violência na escola.

Para compreender a mundialização da violência no espaço escolar evocamos as experiências francesas, canadenses e norte-americanas, as quais representam exemplos de reconhecimento da violência no espaço escolar como uma nova questão social global, cujo símbolo é o silêncio. Para superar tal enclausuramento do gesto e da palavra, há de se descobrir um significado contido nos atos de violência, tarefa da ação pedagógicae das lutas sociais.

Em outras palavras, muitasdasformasde violência contra o patrimônio realizam-se, freqüentemente, sem que ocorra o furto de bens, mas somente sua dilapidação. Esses atos de violência poderiam ser percebidos como reação social contra a escola? Sabemos que os jovens no Brasil atual representam uma geração vitimizada, sem esperanças em relação às promessas de futuro. Antigamente, tais expectativas estavam contidas na proposta da escola, havendo pois um contexto social de gênese da violência escolar. No caso da violência contra a pessoa - lesão corpo ral, rou bo efur to, tráfico de drogas - muitas vezes encontramos 0 uso de armas brancas ou de fogo. E ainda, uma série de alunos apresentava sinais de terem sido vítimas da violência doméstica.

Finalmente, os fenômenosdeincivilidades evidenciam um conflito de códigos de orientação da conduta. Em síntese, identificamos o recurso à violência como forma de obter ganho material ou simbólico; e de resolu ção deconflitos, em dispu tasin terpesso ais.

0 espaço social da violência escolar expressa as crescentes fraturas nas instituições socializadoras, tais como a família e a escola, e um estímulo a condutas desviantes ou ao trabalho na criminalidade, em particular, no tráfico de drogas, o que se reflete ou atinge 0 universo escolar.

Tal fragmentação de laços sociais se exerce pela formação de espaços sociais com predominância de populações pobres e miseráveis, para as quais a violência sistemática pode fa zer par te de um modo de ga nhar a vida edevi ver so ci al men te, epara as qua is a es co la parece relutar em alcançar um relacionamento capaz de incorporar demandas diferenciadas e distintas da matriz disciplinar oficial da instituição escolar.

Saliente- se, ainda, que a relação da escola com as particularidades culturais dos grupos que compõem o espaço social local no qual ela se localiza é, muitas vezes, marcada por uma violência simbólica do saber escolar, exercida por hábitossociais, pelosprofessores e funcionários da instituição, uma relação de poder que impõe um conjunto de valores ao conjunto da população envolvida. Por outra parte, há uma complexidade de tempos sociais na relação e entre a escola e o meio social, o que reforça a importância das atitudes pedagógicas, sociais e culturais dos professores, funcionários e policiais que trabalham nas escolas, e as formas de relacionamento com a coletividade local. Verifica-se, portan- 
to, uma relação entre multiculturalismo versus integrismos, na qual a pluralidade cultural não é trabalhada pedagogicamente sem que haja choques entre os interesses divergentes ou entre as diferentes formas de construção e de classificação da realidade so cial. A escolaéum locus de explosão das conflitualidades da sociedade contemporânea, neste jovem século XXI.

\section{A violência contra o patrimônio}

A compreensão das relações entre a escola e as práticasda vi o lên cia con tra o patrimô nio passa pela reconstrução da complexidade das relações sociais que estão presentes no espaço social da escola. Nos casos em estudo, procuramos desvendar as combinações entre as diversas relações sociais e grupos culturais, localizadas no espaço escolar, a fim decom preender esse tipo de violência.

No caso da cidade de Porto Alegre, estamos em presença de uma rotineira manifestação de violência, que configura um estado de temor das instituições escolares em face do meio social no qual estão inseridas. Segundo dados da Secretaria Municipal de Educação do Município, a maioria das 40 escolas municipais

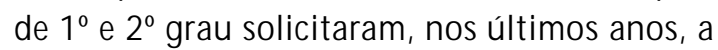
construção de muros, que, muitas vezes, tiveram de ser refeitos ou ter sua localização modificada.

As formas de violência contra o patrimônio mais freqüentes no universo estudado são, em primeiro lugar, os atos de depredação de muros, janelas, paredes, e de salas de aula e de destruição de equipamentos, tais como livros, equipamentos audiovisuais, ou de bens pessoais, em particular os automóveis dos professores. Os furtos aparecem em segundo lugar, principalmente furtos de aparelhos de TV e vídeo, de rádio-cassete, vidros, telhas, brinquedos da escola, alimentos da despensada escola, material escolar, vales-transporte, vasos sanitários, vales- refeição, materiais de educação física e equipamentos computacionais ou audio visuais das escolas. Também foram verificadosfurtosdereló gi oserou bo decarros.

Alguns furtosocorridosno espaço escolarrevelamuma in ten ção cla ra deapro priação de bem alheio:

Entraram derrubando a porta. Na sala de técnicas agrícolas, pegaram uma picareta e arrombaram o portão de grade do barzinho da escola, levaram doces, garrafas térmicas e refrigerantes. Da sala de técnicas no tou-sea falta de dois carrinhos de mão, enxadas e pás de corte. Afastaram a grade da janela da secretaria, arrombaram um armário de aço e levaram um aparelho de som com CD, uma cafeteira elétrica e uma calculadora de mesa.

Se a violência atinge a to dasascamadas sociais, a participação de grupos de identidade jovem é alta. Os grupos mais envolvidos nos atos de violência contra o patrimônio são dejo venseado lescen tes en tre 14 e 18 anos.

Atos de violência na escola são normalmente identificados, por professores, políticos ou pelos meios de comunicação, como atosdecri minali da deou de "van dalismo". Parece-nos que as explicações precisam ser um pouco mais complexas, pois se alguns atos delituosos certamente existem e podem visar os bens das escolas e das pessoas, há outros cuja significação pode ser diversa. Conseguimos identificar atos de depredação, muito freqüentes, sem furto de bens, mas tão-somente sua dilapidação, no próprio espaço escolar, como atos de violência enquanto reação social contra a escola.

Na cidade de São Paulo, Cardia apreendeu um dos significados do vandalismo:

Prédios degradados, grafitados, com ar de vandalizados, convidam a maior degradação e violência. 0 descuido com os prédios sugere uma terra de ninguém, uma terra sem dono que pode ser ocu pa da por aqueleque tem força e coragem para fazê-lo. Para os jovens que 
têm baixa auto-estima, que não conseguem se vincular com a escola devido aos repetidos fracassos, vandalizar a escola (...) é se apropriar dela e, de certo modo, vencê-la. (1997, p. 56)

Nossasinformações nos levaram a identificar esses atos de depredação, freqüentemente sem que ocorra o furto de bens mas tão-somen tesua dila pidação, no pró prio espaço escolar, como atos de violência como reação social contra a escola. Não seria outro o sentido dos seguintes acontecimentos, dentro da sala de aula: alunos, no último período, voltam para a sala de aula, batendo na porta das classes e nas cadeiras, fugindo em seguida; e, significativamente, o caso da professora que sai da sala de aula, deixando seu estojo de giz na mesa e, ao voltar, encontra todos os bastões de giz quebrados no chão. Outras vezes, fica evidente a vontade de entrar no espaço escolar: "Nos fins de semana o pátio da escola é invadido pelos moradores da vila, que destroem os brinquedos e sujam o pátio". E há aquela escola cujas telas do pátio interno foram cortadas, onde houve que bra de vi dros, eatémes mo a que bra delajes de concreto do muro e a retirada de tijolos de uma parede do ginásio. Numa terceira, houve a derrubada de cercas e mourões do Jardim de Infância.

A categoria vandalismo tem sido usada freqüentemente pela imprensa, e também por alguns professores, para identificar atos de violência na escola, embora em reduzido número: tem sido associada à depredação da escola, a arrombamentos, à violência de gangues juvenis, à ocorrência de furtos e roubos. Mas qual 0 significado da categoria vândalo? Parece que se constitui de expressões de um ressentimento social de jovens e adolescentes que foram, ou sesen tem, excluídosdainsti tu ição esco lar, mas que, por vias transversas, querem ser incluídos no espaço escolar.

Evidencia-se uma correspondência entre exclusãosocial e violência escolar: a violência é determinadasocialmente. Tanto mais o público jovem é desfavorecido, em termos econômicos como culturais, tanto mais ele se confronta com a vivência do desemprego, mais ele experimenta uma exclusão, não só de oportunidades econômicas mas também de um pres tí gio so ci al, o queresul ta em umagrava men to de sua auto-estima e de sua perspectiva de futuro. Os jovens vivem hoje a desesperança em relação às promessas de futuro que, antigamente, estavam contidas na proposta da escola: este é o contexto social de emergência da violência escolar.

Reencontramos a escola como ponto de explosão da crise econômica, social, política e cul tu ral, ecomo lu gar deex pres são do ressentimento social. Entretanto, a violência é um discurso da recusa, ela nasce da palavra e dos gestos emparedados, razão pela qual é necessário tentar entender as mensagens escondidas nos atos de violência contra o patrimônio das escolas.

\section{A violência contra a pessoa e o conflito de civilidades}

Os atos de violência contra a pessoa mais comuns nas escolas investigadas foram: casos de lesão corporal, de roubo, de furto e de tráfico de drogas. Também foram registrados casos de alunos que apresentavam sinais de terem sido vítimas de violência doméstica. Entretanto, o recurso à violência como forma de obter ganho material ou simbólico ou de resolução de conflitos, em disputas interpessoais, cada vez mais se manifesta no espaço escolar.

Registramos, em primeiro lugar, furtos de bolsas, de relógios, de dinheiro de funcionários. Mas, também, foram identificados roubos de automóveis, assaltos à mão armada no portão da escola, roubos de dinheiro; em especial, roubos de carros de professores, ou de rádio de carros. Certa vez, uma professora, ao tentar tirar, de dentro da escola, um grupo de alunos que fumavam maconha com 
estranhos, teve seu carro destruído e foi ameaçada de vir a aparecer "com a boca cheia de 'formigas'"; outra "professora enfrentou um aluno, segurando-o pelo braço, mas não pôde sair com o carro, barrada na saída pelos alunos".

Até mesmo assalto e roubo de armas da Guarda Municipal foram registrados. No final do ano de 1998, houve o assassinato de um guarda municipal.

Na maioria das vezes, trata-se da invasão do espaço escolar por pessoas estranhas. Fala-se muito na violência das gangues juvenis, mas pelo menosum caso de rou bo de reló gio de um aluno por outro foi encontrado. A presença de gangues juvenis nas escolastem sido asso ciada à violência: gangues rondando a escola, gangues no período da noite, a violência de gangues juvenis, a formação de várias gangues na escola, gangues que assaltam os alunos na porta da escola, assaltos nas imediações da escola envolvendo gangues.

Os casos de lesões corporais foram registrados contra alunos e contra funcionários. Em três desses casos, encontramos relatos de ameaça de estupro, e mesmo de estupro de fato, no espaço escolar ou em suas cercanias.

0 tráfi co dedro gasno espaço escolartem sido muito presente nos registros, o que implica 0 uso de drogas por alguns alunos e o porte de armas por outros. Freqüentemente, o uso de drogas se dá próximo à escola, em alguma praça, nas imediações. Mas também ocorre dentro do espaço escolar; algumas vezes, os alunos saem da sala, durante as aulas, para comprar drogas.

Talvez a situação em Porto Alegre não seja ainda comparável à do Rio de Janeiro, onde Guimarães indica um duplo efeito da intervenção do mundo do narcotráfico no ambiente escolar. Por um lado, altera toda a organização da vida escolar, interferindo sobre a "cultura da escola", pois "as regras do mundo da rua se intrometem na vida escolar de forma direta (...), em função da necessidade de bus- car, nas regras de convivência com o meio imediato, sua própria condição de sobrevivência"; por outro lado,

a escola termina por ser enredada no mundo da rua naquilo que ele tem de mais perverso: são os padrõesdeilegalida de, davio lên cia privatizada, do mun do vi ril eguer rei ro, da "au to ridade" exercida na base da força física, que envolvem a instituição. (Guimarães, 1998, p. 223-224)

Desse modo, temos que entender a violência como relação de sociabilidade presente na escola, trazida ao espaço escolar por uma dupla fonte: ou como expressão de um autoritarismo pedagógico ou como transferência de uma norma social. A primeira, afirmando uma fórmula repressiva de conduta professoral na sala de aula; a segunda, marcada pela violência que rege as relações interpessoais em grupos sociais particulares, as quais se manifestam como normalidade no cotidiano dos alunos e de suas famílias e, por este entendimento, esta violência doméstica se transfere para o espaço escolar.

Estamos, em grande medida, diante de um conflito de códigos de con du ta, ou conflito de civilidades, como tem sido apontado nos estudos sobre o tema na França e, mais recentemente, em criterioso estudo de caso realizado em liceus de Montevidéu, Uruguai (Viscardi, 1999).

Entretanto, a escola, no caso de Porto Alegre, insere-se em um espaço social, no qual estão presentes os adolescentes e os jovens, ativado por um tecido associativo bastante denso, composto por associações de moradores, escolas de samba, associação de feirantes, sociedades beneficentes, e delegados do orçamento participativo. As demandas que tais associações fazem à escola, além da reivindicação pela educação formal e pela capacitação escolar, são acrescidas de exigências por oportunidades de esportes, de lazer, 
de brinquedos e de recrea ção, eporuma rei vindicação para solucionar os atos de violência interpessoal.

O sistema escolar está em crise, não tem resposta para explicar e ensinar a viver em uma situação de crise das oportunidades de ganhar a vida, pois se trata de um mundo de carência, de tentativa de alcançar equipamentos coletivos mínimos, em um horizonte de exclusão social. Resulta desse processo uma relação ambígua com a instituição escolar, exigida como meio de profissionalização e de transmissão de conhecimento e de valores da cidadania, mas entrecortada pela violência estrutural da sociedade brasileira.

Provocam-se crescentesfraturas nas instituições socializadoras, tais como a família e a escola, e um estímulo a condutas desviantes ou ao trabalho na criminalidade; no universo escolar, o estímulo ao trabalho no tráfico de drogas, em particular. Tal fragmentação social se exerce pela formação de espaços sociais com predominância de populações pobres e miseráveis, para as quais a violência sistemática pode fazer parte de um modo de ganhar a vida e de viver socialmente e com as quais a escola parece relutar em alcançar um relacionamento capaz de incorporardeman das diferen cia dasedistin tas da matriz disciplinar oficial da instituição escolar.

\section{As lutas sociais contra a} violência escolar

Asmobilizações sociaiscontra a violência vêm crescendo na cidade de Porto Alegre mediante grupos de reflexão-ação, campanhas in ternas em sala de aula, passeatas pelos bairros, petições às autoridades municipais e estaduais, declarações à imprensa e tentativas de construir redes de relações sociais com a coletividades locais. Um caminho para uma ação coletiva contra a destrutividade enunciada pela violência, visível nos danos causados ao patrimônio e às pessoas na instituição escolar, repousa na construção de redes de relações sociais densas, em parti cu larcom a co leti vi da dena qual sesitua o estabelecimento escolar.

0 que tem sido perseguido é a realização de uma compreensão, socialmente construída, das mensagens contidas nos atos de violência, ou do significado oculto, obscurecido e, até mesmo, silenciado e implícito em atos de violência ocorridos no espaço escolar. Propõe-se, com tais ações, a difusão de uma ética da solidariedade,cuja base seja o respeito ao outro, exemplificada por uma nova relação entre a escola e os gru posso cia isquedela participam, ou que com ela partilham um mesmo espaço social.

Os programas contra a violência que existem nos principais países têm alguns pontos em comum: a tentativa de satisfação das necessidades dos jovens; o desenvolvimento de um ambiente solidário, humanista e cooperativo; a intenção de criar relacionamentos positivosedu radou rosen treosalu nos, professores e funcionários; a preocupação com um tempo não escolar a ser assumido pela instituição escolar e a ser programado em interação com a comunidade. Ao mesmo tempo, há um objetivo de se incorporar o conflito como uma tensão positiva para a escola, como algo que pode criar coesão social, a escola assumindo o conflito como criador social.

No caso de Porto Alegre, as várias ações de solidariedade com o intuito de reduzir as manifestações de violência contra a escola, ou na escola, realizadas desde $1996,{ }^{7}$ têm sido caracterizadas por palestras e debates sobre violência, por discussões acerca das formas pela quais a violên ciasemanifesta, bem como sobre os meios de combatê-la. Em suma, em todas as tentativas de ação contra a violência, a discussão enfoca os efeitos da violência em relação às dificuldades que ela provoca no andamento pedagógico da instituição escolar.

7. A responsabilidade por tais ações têm sido da SMED da PMPA em convênio com o Grupo de Pesquisa "Violência e Cidadania", do IFCHDA UFRGS. 
Um cami nho parauma ação co leti va contra a destrutividade enunciada pela violência, visível nos danos causados ao patrimônio e às pessoas da instituição escolar, repousa na difusão de uma ética da solidariedade, cuja base é o respeito ao outro, exemplificada por uma nova relação entre a escola e os grupos sociais que dela participam, ou que com ela partilham um mesmo espaço social. Torna-se evidente, no caso em estudo, que o estabelecimento de relações com todos os segmentos da comunidade escolar, ou seja, a construção de um trabalho coletivo,éuma con di ção fun damen tal paraque se possa reduzir os atos de violência.

0 pressuposto de que a violência é o discurso da recusa e que nasce da palavra e do gesto emparedados, que a violência é uma recusa da palavra, a negação do outro como ato social, exige que se tente entender as mensagens implícitas nos atos de violência. Fica claro, portanto, a necessidade de "desnaturalizarmos" a violência, sob pena de, em não o fazendo, acabarmos por banalizá-la a tal ponto que nada mais tocará nossa sensibilidade, tornando-nos cada vez mais duros com o outro, menos solidários e fraternos.

As possibilidades dessa luta social contra a violência também ocorrem no Rio de J aneiro, onde pôde ser constatado que os professores indicaram

o diálogo como prática pedagógica cotidiana utilizada por eles(as) no enfrentamento das situações de violência no cotidiano escolar. Esses(as) professores(as) consideraram que trabalhar 0 tema dentro da sala de aula, através de debates ou atividades que propiciem o diálogo, envolver a criança e conduzir atividades de seu in teressee conquistar a confiança, 0 afeto e a atenção dos(as) alunos(as) são estratégias que podem contribuir para minimizar o problema da violência. (Can dau, Lu cin daeNasci men to,1999, p. 73)

As mobilizações sociais contra a violência nasescolas dePorto Alegreeda região metro po- litana, acima exemplificadas, expressam uma ação coletiva contra a violência. Tal ação realiza uma pedagogia contra a violência capaz de pensar a escola como espaço de construção de uma cidadania que contemple o multiculturalismo e aspirações e necessidades das camadas sociais de jo venseado lescen tes, bem como das coletividades en vol vi dasnainstitu ição escolar.

Perspectivas de pacificação de uma nova escola

A reconstrução dos fenômenos da violência contra a escola e nela, verificados no município de Porto Alegre e na região metropolitana de Porto Alegre, demonstrou que o espaço escolar aparece como ponto de condensação e de explosão da crise econômica, social e política. A compreensão das relações entre a escola e as práticas da violência passa, necessariamente, pela reconstrução da complexidade das relações sociais que estão presentes no espaço social da escola, pois são exatamente as combinações entre relações de classe e relações entre grupos culturais que permitem uma abordagem explicativa das práticas de violência na escola. Precisamos tentar entender as mensagens e os atos escondidos, ou emparedados, nos atos de violência, e ter a audácia de afirmar, contra 0 senso comum e a sociologia convencional, o reconhecimento do con fli to como parteda di nâmica social da escola.

No caso da cidadedePorto Alegre, estamos em presença de uma rotineira manifestação de violências, configurando um estado de temor das instituições escolares em face do meio so cial no qual es tão in seri das. Assim, várias escolas municipais solicitaram a construção de muros, nos três últimos anos, os quais, muitas vezes, ti veram deser refei tosou mo dificados em sua localização.

Entretanto, a escola, em Porto Alegre, insere-se em um espaço social - localizado principalmente na periferia da cidade, tanto 
nazonasu deste como nazona nor tee nor deste do município - , do qual fazem parte os adolescentes e os jovens, mas também em um espaço associativo bastante denso, composto por: associações de moradores, escolas de samba, associação de feirantes, sociedades beneficentes, sin dicatosedelega dosdo orçamen to participativo. As demandas que tais associações fazem à escola, além da reivindicação pela educação formal e pela capacitação escolar, são acrescidas de exigências de oportunidades de esportes, de lazer, de brinquedos e de recreação. Expressam um mundo de carên cia, naten tativa de alcançar equipamentos coletivos mínimos, em um horizonte de exclusão social. No limite, são demandas pela ampliação da cidadania, ou de sua melhor efetivação.

Salienta-se, assim, que a relação da escola com as particularidades culturais dos grupos que compõem o espaço social local no qual ela se encontra é marca daporuma vi olên ciasimbólica do saber escolar. Muitas vezes, essa violência é exercida por hábitos sociais, por modos de vestir ou pelo uso de bens, como o automóvel, pelos professores e funcionários da instituição, uma relação de poder que impõe um conjunto devalo resao con jun to dapo pu lação en vol vida.

Nesse diagrama, há um espaço social marcado por um desencontro entre a instituição escolar e as particularidades culturais das populações pobres das grandes cidades, desencontro que precisa ser substituído por um relacionamento denso en trea esco la eacoleti vi dade local na qual está inserida (Graciani, 1995, p. 145; Zaluar, 1992). Esta também foi a conclu são de Car dia, para a ci da de de São Pa u lo: "é necessá rio queasesco lasen vol vam etra balhem não só com os alunos, mas também com suas famílias e com as comunidades onde estão situadas" (1997, p. 64). Passa a ser, também, indicada como um desafio aos educadores:

0 processo de sensibilização e conscientização danecessidadedelu tarcon traa vio lên ciaéfunção que a escola pode e deve assumir, engajan- do-se junto com a sociedade na busca de sinais de vida para enfrentar a destruição e a morte. (Assis, 1994, p. 22)

Emváriasso ciedades, naatuali da de, estão se realizan do reflexõesemovimen tospara reduzir a violência na escola. Na França, por exemplo, um grupo filiado à pedagogia institucional propôs: 1. Criar instituições em cada sala de aula, ou seja, regras, leis, o Conselho de Classe, a fim de converter o espaço de cada sala de aula em uma rede de relações; 2 . "Levar em conta os conflitos e organizar os meio para sua resolução"; 3. Expandir o senso de responsabilidade dos estudantes; 4. Estabelecer em cada escola uma lei fundamental, que "fixa os limites nos quais vão se exer cer ospoderes de cada um", enquanto um "limite do campo do possível", efetivando um aprendizado da liberdade vivida no cotidiano; 5 . Estabelecer espaços para o falar, criando lugares e tempos para a palavra de modo a desenvolver "um sistema de enunciação legíti ma" (Co lom bi er, 1994, p. 82, 88, 101 e 108).

Essa proposta implica a construção institucional da escola, permitindo a possibilidade de espaços da linguagem e do falar, respeitando as temporalidades diferenciais e os estilos variados de expressão cultural, pois a presença de grupos sociais e culturais diversificados exige o reconhecimento do multiculturalismo (Sousa Santos, 2000, passim).

Nasociedade norte-americana, as origens da violência na escola parecem estar nas mudanças dos padrões da família e da vida comunitária (Remboldt, 1994, p. 6; Kreiner, 1966, p. 22; J ohnson, 1995) e no fato de que a sociedade americanaredefiniuaviolên ciacomo normal e aceitável (Remboldt, 1994), o que, certamente, foi estimulado pela presença da violência na mídia (Kreiner, 1966, p. 26) e pelo fácil acesso a armas e a drogas (Kreiner, p. 23 ). Por outro lado, os jovens sentem-se habilitados para a violência e tolerados pelos professores e pais (Remboldt, 1994, p. 13; Kreiner, 1966, p. 36). 
Nesse contexto, uma série de programas foram desenvolvidos para prevenir a violência, com base nos seguintes princípios: procurar a satisfação de necessidades das crianças e jovens (Hyman, 1997, p. 315); desenvolver um ambiente cooperativo com relacionamentos positivos e duradouros (Kreiner, 1996, p. 41); utilizar o tempo não-escolar (Kreiner, 1966, p. 55); e promover a interação com a comunidade (Remboldt, 1994, p. 29; Hyman, 1997, p. 316). Trata-se, em suma, de instaurar práticas de negociação e de resolução de conflitos com as es colas, assumindo que as conflitualidades podem se transformar em forças de positividade na dinâmica escolar.

Desta forma, os programas contra a violência escolar que existem no mundo apontam para a busca de uma escola que propicie um espaço solidário, humanista e cooperativo, em permanente interação com a comunidade, enfim um espaço prazeroso de construção da cidadania.

O ca mi nho parauma ação co leti va con tra a destrutividade enunciada pela violência, visível nos danos causados ao patrimônio eàs pessoas da instituição escolar, repousa na difusão de uma ética da solidariedade, cuja base seja 0 respeito ao outro, exemplificada por uma nova relação entre a escola e os grupos sociais que dela participam, ou com ela partilham um mesmo espaço social. 0 estabelecimento de relações com todos os segmentos da comunidade escolar, ou seja, a construção de um trabalho coletivo, éuma con di ção fun da men tal para que se possa reduzir os atos de violência.

No caso da violência na escola, evidencia-se que o conflitosocial, enten didoenquanto um processo de interação social ou de so ci ali zação, quepo deim pli carum pro cesso de coesão do gruposo cial, possibilitaacompreensão de to dasaspo si çõesem dispu tanainsti tu ição escolar que vivencia situações de violência. Aparentemente, trata-se de uma repetição de um processo de "ruptura dos laços sociais", marcado pela desfiliação (Castel, 1998) dos estudantes a grupos sociais de referência - a família e a escola - e pela busca de novos laços so ciais- asgan gueseosgru poscul tu ra is.

Também a Unesco propõe uma série de medidas antiviolência, propostas que podem ser localizadas em outros estudos recentes (Unesco, 1977):

- se "a violência começa na mente humana", deve-se desenvolver uma cultura da pacificação. No caso da América Latina, a crise social e política exige um grande esforço neste sentido, como afirmam membros do Save the Children Fund (UK): "Iniciativas têm sido criadas em torno de idéias como 'educação para a paz', e 'educação para a democracia', as quais pretendem combater a mentalidade cada vez mais generalizada de violência, para dirigir o processo de socialização das crianças em direção à paz, contra a violência e fomentan do 'orespeito à vida'" 8

- promover o estabelecimento de políticasde antiviolência na escola. Nessa linha, Prochazka sugere que, no interior do estabelecimento escolar, seja privilegiado o diálogo e a escuta, pouco importando qual o interlocutor, pois

0 essencial é que o conflito virtual ou efetivo possa ser dito, verbalizadoa alguém que não é parte do conflito. Freqüentemente, a palavra, como na tragédia antiga, desempenha seu papel de catharsis e purifica as paixões em presença do que contém de maximalismo, de vontade irremediável. Falar é se colocar em cena, é se descentrar em relação a si mesmo, é se distanciar. (Prochzka, 1996, p. 82)

- estimular a interação e cooperação entre os professores e funcionários e os alunos;

8. Salazar, Maria Cristina \& Oakley, Peter. Ninos y violencia : el caso de América Latina. Colombia: Tercer Mundo Ed., 1993. p. 185-186. 
- en fren taro pro blema da vi o lên cia por den tro do currículo escolar;

- promover a cooperação escola - comunidade. (Unesco, 1977).

Em todas essas medidas, os administradores escolares e os professores devem ser estimulados a se reconverterem em educadores. Prochazka sugere uma formação permanente para compreender e para agir sobre a violência na escola, o que permitiria:

falar da violência propiciando oportunidadesde troca acerca de um tema freqüentemente vivido como inabordável, tomar uma certa distância e, assim, reduzir os medos; identificar coletivamenteindicado resreveladores, disfuncionalidades, perceber e compreender a natureza das violências (agressão, agressividade, conflito, violência física ou verbal, empurrões, etc.); começar a construir respostas visando encontrar boas comunicações, desenvolver a responsabilidade, restaurar as con di ções de base de uma relação pedagógica e educativa. (Prochzka, 1996, p. 116)

Surge uma agenda de trabalho sobre reduzir ou erradicar a violência na escola, fundada, inicialmente, na produção de informação sistemática sobre o fenômeno, a fim de retirá-lo do manto do medo, da vergonha e da insegurança; depois, produzir a formação dos educadores sobre a violência contemporânea, a fim de que saibam manejá-la e convertê-la em objeto pedagógico; finalmente, desenvolver a comunicação dialógica entre pais, professores, funcionários e os alunos, a fim de conhecer 0 fenômeno, suas origens e causas sociais e poder, assim, superar o sofrimento causado pela violência na escola.

A esperança renasce ao observarmos as ações contra a violência na escola. Os programas contra a violência que existem nos principais países, inclusive em algumas escolas de Porto Alegre, desenvolvem a metodologia de mediação de conflitos como uma das propostas de pacificação do espaço escolar.

Isto significa assumir uma prática de negociação instaurada no interior da escola, em especial nos próprios grupos de alunos, por meio, por exemplo, da idéia de mediação pelos pares, de forma a criar responsabilidades entre os próprios membros da escola, na tentativa de satisfazer as necessidades dosjo vens mediante o desenvolvimento de um ambiente solidário, humanista e cooperativo.

Por um lado, a intenção é a de criarrelacionamentos construtivos entre alunos, professores, funcionários e pais; por outro, expressar a preocupação com 0 tempo não-escolar a ser assumido pela instituição escolar, e outras agências estatais, em interação com a coletividade local.

De qualquer modo, o objetivo é incorporar o conflito como uma tensão positiva para a escola, como um processo que pode criar coesão social, des dequeaescolaassu ma pedagogicamente o conflito como criador de relações sociais.

Muitas são as ações de solidariedade possíveis, afim dereduzirasmanifestaçõesde violência contra a escola, ou na escola. Trata-se de um processo de construção da paz, que reconhece a escola como espaço de construção de uma cidadania que contemple 0 multiculturalismo, reconheça as aspirações e necessidades das camadas sociais de jovens e adolescentes, e passe a uma regularidade de inclusão das coletividades locais com a instituição escolar. Delineia-se a perspectiva de construir na escola um espaço de construção doconhecimen to criativo, um processo dedesenvolvimento da personalidade reflexiva, no qual se realize o reconhecimento da dignidade humana e se desenvolva o processo de construção de uma cidadania mundial e multicultural. A Sociologia pode contribuir nesta caminhada pelo arco-íris de uma juventude que precisa reencontrar o sentido da existência em paz e liberdade. 


\section{Referências bibliográficas}

ASSIS, Simone Gonçalves de. Crescer sem violência - um desafio para os educadores. Rio de J aneiro: Fundação Osvaldo CrUz - CLAVES, 1994.

CANDAU, Vera; LUCINDA, Maria da C.; NASCIM ENTO, Maria das Graças. Escola e violência. Rio de J aneiro: DP \& A, 1999.

CASTEL, Robert. As metamorfoses da questão social . Petrópolis: Vozes, 1998.

CARDIA, Nancy. Violência urbana e a Escola. In: Revista contemporaneidade e educação. Rio deJ aneiro, IEC, ano II, n. 2, p. 26-69, 1997.

CHARLOT, Bernard \& EMIN, J ean-Claude. Violences à l'école: état des savoirs. Paris: Armand Colin, 1997.

COLOMBIER, Claude et al. A violência na escola. São Paulo: Summus, 1989.

DEBARBIEUX, Eric. La Violence en milieu scolaire - 2. Le désordre des choses. Paris: ESF, 1999.

DEFRANCE, Bernard. La violence à l'école. Paris: Syros, 1992.

ELIAS, Norbert. 0 Processo civilizador - uma história dos costumes (vol. 1). Rio de J aneiro: J orge Zahar, 1990. . 0 Processo civilizador - formação do Estado e civilização (vol. 2). Rio de J aneiro: J orge Zahar, 1993.

ERIC Debarbieux, In: Homepage do Ministère de I'Education Nationale, France, 3 de abril de 1997.

GIDDENS, Anthony. Para além da Esquerda e da Direita. São Paulo: Editora da Unesp, 1996.

GRACIANI, Maria Stela Santos. Gangues: um desafio político-pedagógico a ser superado. In: HERON, L. (org.). Reestruturação curricular. Petrópolis: Vozes, 1995.

GUIMARÃES, Eloisa. Escola, galeras e narcotráfico. Rio de J aneiro: Editora da UFRJ , 1998.

GUIM ARÃES, Áurea M. A dinâmica da violência escolar: conflitos e ambigüidades. São Paulo: Ed. Autores Associados, 1996.

HARVEY, David. A Condição Pós-moderna. São Paulo: Loyola, 1993.

HEBERT, J acques. La violence à l'école (guide de prévention et techniques d'intervention). Montreal: Logiques, 1991.

HYMAN, Irwin et alii. School discipline and school violence: the teacher variance. Boston: Allyn and Bacon, 1997.

IANNI, Octávio. A Era do Globalismo. Rio de J aneiro: Civilização Brasileira, 1996.

. A Sociedade Global. Rio de J aneiro, Civilização: Brasileira, 1992.

J AMESON, Fredric. Pós-modernismo : a lógica cultural do capitalismo tardio. São Paulo: Ática, 1996.

JOHNSON, DAVID W.; JOHNSON, ROGER T. Reducing School Violence through Conflict Resolution. Alexandria: ASCD, 1995.

KREINER, Anna. Everything you need to know about School Violence. New York: The Rosen Pub Group, 1966.

LUCAS, Peter. Pequeno relato sobre a cultura da violência no sistema escolar público em Nova York. In: Revista contemporaneidade e educação. Rio de J aneiro, IEC, ano II, n. 2, p. 70-95, 1997.

OHSAKO, Toshio (ed.). Violence at School : global issues and interventions. Paris: Unesco, 1997. 
PERALVA, Angelina. Escola e violência nas periferias urbanas francesas. In: Revista contemporaneidade e educação. Rio de J aneiro: IEC, ano II, n. 2, p. 7/25, 1997.

PROCHZKA, J ean-Yves. Agir face à la violence. Paris: Hachette, 1996.

REMBOLDT, Carole. Solving Violence Problems in your School. Minneapolis, J ohnson Institute, 1994.

SILVA, L. H. ; AZEVEDO, J.C. e SANTOS, E. S. (orgs.) Novos mapas culturais, novas perspectivas educacionais. Porto Alegre: Sulina, 1996.

SOUSA SANTOS, 1994, Boaventura. Pela mão de Alice: 0 social e o político na pós-modernidade. Porto: Afrontamento, 1994.

SPOSITO, Marília Pontes. A sociabilidade juvenil e a rua: novos conflitos e ação coletiva na cidade. In: Tempo Social. São Paulo, USP, v. 5, n. 1-2, p. 161-178, s.d.

TAVARES DOS SANTOS, José Vicente (org.). Violências em tempo de Globalização. São Paulo: Hucitec, 1999.

; NERY, Beatriz Didonet; SIM ON, Cátia Castilho. A palavra e o gesto emparedados : a violência na escola. Porto Alegre: PMPA - SMED, 1999.

VISCARDI, Nilia. Violência no espaço escolar: práticas e representações. Porto Alegre;1999. Dissertação (Mestrado em Sociologia) - IFCH da UFRGS.

ZALUAR, Alba (org.) Violência e educação. São Paulo: Cortez, 1992.

. Condomínio do diabo. Rio de J aneiro: UFRJ, 1994.

Recebido em 04.09 .01

Aprovado em 11.09 .01

José Vicente Tavares dos Santos é professor titular do Departamento de Sociologia e docente do Programa de Pós-graduação em Sociologia da Universidade Federal do Rio Grande do Sul. É presidente da Sociedade Brasileira de Sociologia, membro do ConselhoNacional da SBPC e da diretoria da ALAS - Associação Latino-AmericanadeSociologia. 